\title{
UPACARA BIYUKUKUNG (Kearifan Lokal Masyarakat Bali dalam Menjaga Teo-Agrikultur)
}

Ni Nyoman Suastini ${ }^{1}$

Universitas Hindu Negeri I Gusti Bagus Sugriwa Denpasar

\begin{abstract}
Biyukukung ceremony was carried out by Balinese people who worked in agriculture, especially rice farming. This ceremony was related with Balinese people's effort religiously to gained prosperity for their rice in the field. As a rice farmer, Balinese people often had adversity in their field, liked damaged by pests, lacked of water, and more. As a religious people, they used this ceremony to avoid any adversity. Biyukukung ceremony was carried out by farmers, started from prepared the facilities like banten and other which related with the ceremony. The meaning of this ceremony was an expression of farmers' thankful to God in the form of his manifestation as Dewi Sri and Dewa Wisnu which provided safety and growth the rice fertilely, protected from the pests, and other damaged. That was why Balinese people carried out the ceremony which had inherited by every generation. This ceremony also made different meaning of agriculture group, which was not only about farming. Moreover, the mean was combined the concept of Hindu's theology and farming. This tradition then became a unified in farming system, so that the religion ceremony and farming activity be related to each other. Balinese people always depended to God for their safety, so that all of their action, included farming, was related. This relation made Bali unique, there was no line between religion and culture in their daily life. Thus, "Biyukukung Ceremony" had function and meaning to prayed the rice growth fertilely and also the field safety, so that the farmers could harvest well according to their expectation.
\end{abstract}

Keywords Biyukukung Ceremony, Theology, Agriculture, Rice Field, Rice

\footnotetext{
1 nyomansuastini@gmail.com
} 


\section{PENDAHULUAN}

Masyarakat Bali adalah suatu komunitas unik dibelahan bumi Indonesia ini yang memiliki karakter struktur dan konstruksi sosial yang menarik untuk dikaji. Tidak hanya karena karakter masyarakatnya yang seringkali nampak homogen, tetapi karena wujud manifes kebudayaannya yang melembaga dalam setiap ranah kehidupan masyarakatnya yang mayoritas beragama Hindu. Manifestasi kebudayaan masyarakat Hindu di Bali tercermin dalam setiap perilaku kehidupan sehari-hari. Menariknya dalam masyarakat Bali, ritual budaya dan ritual keagamaan seringkali tidak menunjukkan perbedaan yang signifikan. Seolah, praktik ritual keagamaan dan juga kebudayaannya selalu menunjukkan sebuah dialektika satu sama lain. Antara keduanya telah berwujud menjadi satu kesatuan 'ritualitas' yang sama sebagai bentuk penghayatan atas ajaran keagamaan (Hindu) yang mengendap dalam praktik-praktik kebudayaannya selama ini.

Masyarakat Bali sebagai penganut taat Hindu dalam praktik kehidupan seharihari berupaya men-sinergi-kan tradisi kefilsafatan, budaya dan sekaligus agama dalam suatu bentuk manifestasi kebudayaan. Sehingga wujud kebudayaan yang muncul dalam masyarakat Bali merupakan suatu bentuk kebudayaan yang di dalamnya mengandung suatu bentuk kefilsafatan dan ajaran agama. Masyarakat Bali pemegang teguh adat istiadat tidak bisa terlepas dari upacara-upacara adat dan keagamaan, yang menyebabkan Bali mempunyai pesona yang bisa membuat orang tertarik dan terkagum. Pulau Bali di kenal sebagai daerah pariwisata dikarenakan adat istiadat dan budayanya. Masyarakat Bali tidak luput dari upacara Yajna hampir setiap hari, orang Bali selalu melaksanakan yajna dari yang paling sederhana sejumput nasi setelah memasak, sampai pula Tawur atau Caru Ekadasa Rudra yang di laksanakan seratus tahun sekali, semua bahan yajnya tersebut dahulunya berasal dari hasil pertanian di Bali yang di persembahkan kepada Tuhan sebagai wujud rasa bhakti (Sudarsana, 2017).

Hasil pertanian yang melimpah tidak terlepas dari kepercayaan masyarakat Hindu Bali akan tradisi turun temurun. Tradisi pertanian masih mempertahankan aspek religius dalam bercocok tanam. Hal ini terlihat jelas dalam penerapan budaya upacara seperti mulai adanya budaya upacara yang dilakukan oleh kaum wanita tani sebelum mengolah tanah pertanian, pelaksanaan upacara saat memulai bercocok tanam bahkan setelah panen hasil pertanian upacara tetap dilaksanakan sebagai bentuk ucapan terima kasih kepada pencipta atas hasil panen yang diterima petani. Kaum wanita tani telah menerapkan budaya ini dari jaman dahulu, ada kepercayaan yang timbul secara turun-temurun terhadap adanya suatu yang baik dan yang buruk dari alam.

Kepercayaan terhadap pelaksanaan budaya pertanian di dalam masyarakat Bali sudah lama dikenal. Upacara pertanian dilakukan secara bertahap dari pengolahan lahan hingga panen tiba. Upacara lain yang masih berkaitan dengan pertanian dilakukan pada waktu pertama kali memasukkan padi ke lumbung (munggah lumbung). Hal ini disebabkan adanya kepercayaan bahwa tanaman padi berasal dari tubuh Dewi Sri. Oleh karena itu timbul suatu pandangan sakral terhadap lumbung. Kesakralan inilah yang menyebabkan lumbung sebagai tempat penyimpanan padi diperlakukan sebagai tempat yang suci bagi masyarakat yang bermata pencaharian sebagai petani. 
Upacara biyukukung adalah termasuk salah satu rangkaian dari upacara Dewa Yajna. Upacara biyukukung merupakan upacara yang ditujukan pada tumbuhan padi yang akan tumbuh buah atau padi yang sedang mengandung. Upacara biyukukung sesuai dengan ajaran Agama Hindu dan kepercayaan masyarakat dilaksanakan agar nantinya padi tumbuh dengan subur dan hasil panenan melimpah ruah. Ritual biyukukung ini adalah ritual untuk tanaman padi yang mulai ngidam (beling). Atau upacara (ritual) saat tanaman mulai mengandung. Ritual biyukukung ini adalah ritual untuk menghilangkan bahaya (untuk keselamatan) padi yang sedang hamil dan siap untuk melahirkan (Bandana, dkk. 2010). Upacara biyukukung juga disebut ngiseh. Secara umum tujuan ritual ini adalah agar tanaman padi berbuah lebat (samah, nged) jauh dari segala macam gangguan dan bahaya

Upacara biyukukung ini mengambil lokasi pada Subak Pupuan Luwah, Desa Gadungan, Kecamatan Selemadeg Timur, Kabupaten Tabanan, karena upacara tersebut sangat unik, baik dari sarana yang digunakan, yaitu sebuah 'keroso' dari anyaman daun kelapa yang dibentuk melingkar yang menyerupai corong, dan 'penjor' yang berisi hiasan burung-burungan sedang terbang yang terbuat dari serabut kelapa dan diberi sayap bulu ayam.

\section{METODE PENELITIAN}

Penelitian ini menggunakan metode penelitian kualitatif, dikatakan demikian sebab hasil-nhasil dari semuannya tak didapatkan melalui prosedur statistik atau pun hitungan lainya. Penelitian ini bukan membutuhkan rangkaian angka-angka tetapi lebih banyak membumtuhkan jenis data yang berbentuk rangkaian kata-kata. Prosedur penelitian ini menghasilkan data deskriptif berupa lisan, kata-kata tertulis, dan prilaku orang-orang yang dapat diamati. Jenis data kualitatif yang diperoleh bersumber dari data primer dan data skunder Penentuan informan dalam penelitian ini menggunakan teknik Purposive Sampling, yang merupakan teknik penentuan informan dengan akurasi dapat memberikan data yang diperlukan sesuai dengan tujuan peneliti. Metoda pengumpulan data dalam penelitian ini adalah wawancara, observasi, dan pencatatan dokumen dengan analisis data dilakukan melalui tiga jalur kegiatan yaitu : 1) data reduction (reduksi data), 2) data display (penyajian data), 3) conclusion drawing (verifikasi).

\section{HASIL DAN PEMBAHASAN}

\section{Bentuk Upacara Biyukukung}

Upacara Biyukukung berasal dari kata "upacara dan biyukukung". Kata upacara sendiri berasal dari "upa" yang berarti 'berhubungan dengan', dan "cara" dari urat kata "car" yang berarti gerak, kemudian mendapat akhiran "a" menjadi kata benda yang berarti "gerakan". Jadi upacara adalah gerakan (pelaksanaan) daripada upakara-upakara dalam suatu yadnya untuk memuja Ida Sang Hyang Widhi Wasa beserta manifestasinya. Menurut Mas-Putra (2000: 6) kata upacara sama artinya dengan 'aci', 'karya', yaitu upacara untuk memohon kehadapan Ida Sang Hyang Widhi Wasa agar diberikan keselamatan dan kesejahteraan untuk semua mahluk. Dengan demikian, dari sudut pandang filsafat, upacara adalah cara-cara melakukan hubungan antara Atman dengan Paramatman, antara manusia dengan Hyang 
Widhi, serta dengan semua manifestasi-Nya dengan jalan yadnya untuk mencapai kesucian jiwa. Untuk upacara-upacara ini dipergunakanlah upakara sebagai alat penolong agar dapat memudahkan manusia menghubungkan dirinya dengan Ida Sang Hyang Widhi Wasa dalam bentuk yang nyata (Mas-Putra, 2000: 6). Wikarman (1995) dalam bukunya yang berjudul "Aci-aci Bercocok Tanam Padi", menguraikan tentang rentetan upacara padi serta maksud dan tujuan dilaksanakannya upacara tersebut, dari sejak pengolahan tanah sampai pada padi disimpan di lumbung. Pada Lontar Bhagawan Sukra, disebutkan seperti berikut;

"Nyan tingkahing nandur pari ring sawah, yayan nuasen iki wilangan bulih..., iki mantranya "Ong anasira Rsi Gana rupa kadiliman matadumilah angilangakena sasab merana wigenaning pari. Ong Ung Pat, iki bantenya cawu petik 6 (nenem), cawu mumbul 1 (asiki)". Sampun matuwuh duang puluh dina; nasin pulung 4 (papat), ketipat pandawa 2 (dadua), matuwuh duanglek blayag 6 (nenem), katipat genep 1 (asiki), asem, punyan phala, klungah kinasturi, matuwuh tiganglek majerimpen abyukukung ngaranya..., iki mantran banten mabyukukung "Pakulun Bhatara Sri sangayusa maduning dukut ira nini angirutaken Sri kabeh, Ong Sanghyang Sika tan koya langgana irutaken parisawah angetana paraknarigaga sawah ingulun, Sang Metri tan koya langgana angirutakena parisawah anglone parakena rigaga sawah inghulun, Sang Kurusya tan koya langgana irutakena parisawah anglone parakna rigaga sawah ingulun, ri madya Sang Pretenjala araningulun ong astu swaha" (Lontar Bhagawan Sukra, Nomor: 3b).

Terjemahannya:

Kalau hendak bercocok tanam padi disawah inilah hal-hal yang harus diperhatikan; pada saat mulai menanam padi (nuasen) ini jumlah bibit yang harus di tanam..., ini mantranya "Ong anasira Rsi Gana rupa kadiliman matadumilah angilangekena sasab merana wigenaning pari, ong ung pat. Ini banten/ upakaranya; cawu petik 6 (enam), cawu mumbul 1 (satu)". Sesudah padi berumur duapuluh hari, ini upakaranya; nasi pulung 4 (empat), ketupat pandawa 2 (dua), berumur dua bulan, ini upakaranya; blayag 6 (enam), ketupat genep 1 (satu), asem, pohon phala, klungah kinasturi, dan sesudah padi di sawah berumur 3 bulan (hamil) upacara abyukukung/mabyukukung namanya; ini mantranya "Pakulun Bhatara Sri sangayusa maduning dukut ira nini angirutaken Sri kabeh, Ong Sanghyang Sika tan koya langgana irutaken parisawah angetana paraknarigaga sawah ingulun, Sang Metri tan koya langgana angirutakena parisawah anglone parakena rigaga sawah inghulun, Sang Kurusya tan koya langgana irutakena parisawah anglone parakna rigaga sawah ingulun, ri madya Sang Pretenjala araningulun ong astu swaha".

Demikian seluk beluk menanam padi disawah menurut Lontar Bhagawan Sukra, dengan harapan supaya para petani sawah mendapatkan hasil yang baik dan 
sesuai dengan harapannya. Sedangkan kata 'biyukukung' kalau dicermati dari asal katanya berasal dari kata 'beya' dan 'kukung'. Beya artinya 'biaya', 'upakara' dan 'kukung' berasal dari kata 'kung' yang berarti asmara, cinta. Jadi upacara ini dimaksudkan untuk memohon kepada manifestasi Ida Sang Hyang Widhi Wasa agar padi yang sedang mengandung disawah atau pertemuan asmara antara kepala putik dengan tepung sari dan berlanjut terjadinya pembuahan, berhasil dan selamat (Wikarman, 1995: 22). Asmara yang dimaksud dalam pembahasan ini adalah asmara antara Bhatara Sri dengan Bhatara Wisnu.

Di dalam tumbuhan padi, asmara yang dimaksud adalah pertemuan antara putik dengan tepung sari yang terjadi dalam proses pembuahan. Dalam keadaan ini padi yang sedang dipelihara akan mengalami pertumbuhan lebih lanjut sehingga dapat hamil (mengandung buah) dan selanjutnya dapat menghasilkan padi sebagaimana yang diharapkan. Karena pada saat terjadi pertemuan antara putik dan benang sari diyakini sebagai awal terjadinya pembuahan. Pertemuan inilah yang diperingati dengan sebuah upacara yang disebut 'upacara biyukukung'. Jadi upacara biyukukung dalam penelitian ini adalah upacara yang dilakukan oleh para petani sawah untuk memohon kepada Ida Sang Hyang Widhi Wasa/ Tuhan Yang Maha Esa dalam manifestasi-Nya sebagai Dewi Sri dan Dewa Wisnu, agar padi yang sedang tumbuh diberikan kesuburan, keselamatan, berbunga, dan berbuah yang lebat, supaya para petani dapat panen melimpah ruah sesuai dengan harapannya.

\section{Sarana Upacara Biyukukung:}

Sarana upakara merupakan kelengkapan yang mendukung pelaksanaan upacara keagamaan. Dengan adanya sarana upakara ini dapat membantu seseorang dalam pengamalan ajaran bhakti, seperti yang tercantum dalam Bhagawad Gita IX. 26, berikut ini;

Pattram puspam phalaṃ toyam yo me bhaktyā prayacchati, tad aham bhaktyauppahritam aśnāmi prayatatmanaḥ.

Terjemahannya :

Siapa saja yang sujud kepada Aku dengan persembahan sehelai daun, sekuntum bunga, sebiji buahbuahan, seteguk air, Aku terima sebagai bakti persembahan dari orang yang berhati suci (Pudja, 2004: 220).

Kutipan sloka di atas mengingatkan manusia agar selalu beryadnya, karena yajna itu adalah kebajikan dan kebajikan adalah dharma. Bagaimanapun bentuk yajna itu akan tetap diterima oleh Sang Hyang Widhi asal dilandasi dengan keikhlasan hati. Dengan melaksanakan yajna berarti seseorang kembali ke jalan sang pencipta, karena yajna adalah dharma, sedangkan Sang Hyang Widhi Wasa adalah sumber dharma. Sedangkan upakara adalah bagian dari yajna yang kasat mata sebagai pengejawantahan dari rasa bhakti dan perbuatan kebajikan (subhakarma).

Upakara juga dapat dipergunakan sebagai sarana untuk menyampaikan rasa sujud bhakti, memohon keselamatan, memohon maaf kehadapan Ida Sang Hyang Widhi Wasa atau manifestasi-Nya yang dihadirkan dalam suatu upacara (Arwati, 2005: 3). Upakara sesungguhnya merupakan 
perwujudan dari bhakti marga dan karma marga, manusia dilahirkan semua sebagai pemuja bentuk, memuja bentuk diartikan suatu hal yang baik, karena termasuk dalam lingkungan sifat-sifat perangai manusia. Selama melihat dunia ini yang ada dimuka dengan berbagai corak dan bentuknya selama itu juga kita tidak lebih sebagai pemuja bentuk. Seseorang yang tidak dapat menangkap pengertian-pengertian yang abstrak, tidak dapat melihat dirinya dengan sewajarnya, kecuali dengan memakai pertolongan dari benda-benda yang berjasad, sebagai bahan dan jasmani dia adalah pemuja bentuk (Wijayananda, 2006 : 94).

Apabila dicermati banten yang demikian banyak dan bentuknya bermacammacam serta bahannyapun memang kelihatan rumit dan unik. Namun, dibalik kerumitannya tersebut tentu mempunyai arti yang mendalam, mengandung simbolik dan makna yang tinggi serta terpadu dengan nilai-nilai seni yang sangat mengagumkan. Faktor seni dalam beragama Hindu sangat diperlukan untuk meningkatkan rasa (pangerase bahasa Bali) dari seseorang adalah suatu hal yang positif, karena memegang peranan penting untuk menunjang pelaksanaan upacara agama dalam memantapkan keyakinan. Banten juga memegang peranan yang penting karena dapat digunakan sebagai alat konsentrasi dalam memuja Tuhan/ Ida Sang Hyang Widhi Wasa.

Berkonsentrasi akan dapat membawa ketenangan jiwa yang merupakan faktor penentu dan mempunyai peranan penting dalam mencapai pemusatan pikiran. Untuk memohon ketenangan batin diwajibkan selalu mengabdikan diri dengan menjalankan kewajiban-kewajibannya, yakni dengan melakukan perbuatan yang ditujukan kepada kesejahtraan orang lain, baik yang bersifat duniawi maupun rohani tanpa mengharapkan balasan/ imbalan. Semua itu disebut dengan yajna. Di samping itu upakara atau banten merupakan pengejawantahan dari ajaran-ajaran Agama Hindu, sebagai wahana pembelajaran diri untuk meningkatkan kualitas hidup serta untuk menuju kehidupan spiritualitas. Yajna juga sebagai sarana mendekatkan diri kepada Tuhan Yang Maha Esa, dengan tujuan untuk penyatuan Sang Hyang Atma dengan Sang Hyang Paramatma atau "manunggaling sang sinembah kalawan sang kasembah" (Wijayananda, 2006: 1).

Dalam upakara ada enam aspek yang harus dicermati atau dipahami sebagai pembelajaran diri untuk mewujudkan keseimbangan jiwa dan meningkatkan kualitas hidup menuju kehidupan jagadhita yaitu:

1. Upakara sebagai sarana menyebarluaskan ajaran Agama (Weda); upakara adalah yatra atau simbolsimbol dalam kehidupan beragama Hindu, hendaknya dapat dipahami dan dihayati akan makna dan tujuannya, upakara atau simbol-simbol keagamaan tanpa dibarengi dengan pemahaman yang baik dan benar, maka upakara tersebut tidak akan berarti apa-apa.

2. Upakara sebagai penyeberangan atma menuju kelepasan; yaitu upakara adalah wujud sebagai kewajiban terhadap tri rna (tiga hutang). Dalam Manawadharmasastra, VI.35 disebutkan pikiran baru dapat ditujukan kepada kelepasan setelah tiga hutang kita terbayar. Diwujudkan dengan tapa, yajna, kerti yang dilandasi dengan ketulus-ikhlasan sebagai wujud bhakti, tanpa terikat akan hasil atau imbalan jasa. 
3. Upakara sebagai sarana untuk menyampaikan permohonan kepada Ida Sang Hyang Widhi Wasa; divisualisasikan dalam bentuk banten dalam rangka menurunkan Siwa (Tuhan) dibumi menurut konsep siwalingga untuk memohon agar Beliau berkenan melimpahkan kebahagiaan atau kesejahteraan kepada semua mahluk untuk terwujudnya jagadhita.

4. Upakara sebagai sarana untuk menciptakan keseimbangan; upakara memiliki arti mendekatkan diri yang dilandasi dengan cinta kasih yang tulus dalam mewujudkan tri hita karana, yakni; hubungan manusia dengan sang pencipta, manusia dengan sesama umat manusia, dan manusia dengan alam lingkungannya.

5. Upakara sebagai sarana untuk menciptakan kesucian dan penebusan dosa; upakara sebagai sarana menciptakan kesucian dapat kita lihat dari penggunaan alat-alat upacara tersebut.

6. Upakara sebagai sarana mendidik yang bersifat praktis; hal tersebut menyangkut tata laku pengamalan ajaran agama dalam kehidupan seharihari (Wijayananda, 2006: 97).

Enam aspek di atas dapat dilihat pada setiap pelaksanaan upacara. Apapun bentuk upakara yajna yang dipersembahkan pastilah memiliki tujuan untuk mewujudkan keseimbangan jiwa dan mencapai kehidupan yang jagadhita. Hal tersebut dapat dicermati pada setiap pelaksanaan upacara panca yajna yang selalu saja menggunakan sarana upakara/ banten sebagai pelengkapnya. Menurut Ganter (Wawancara, 21 Februari 2018) sarana upakara atau banten yang dipergunakan dalam pelaksanaan upacara biyukukung adalah sebagai berikut;

\section{Banten Sorohan}

Terdiri dari: dua buah tumpeng, tiga buah kulit tulung diisi nasi kemudian diisi raka-rakaan, seperti; bantal, tape, tebu, buah-buahan, jajan, kacang-kacangan (rerasmen) lalu di atasnya diisi sampiyan pelaus. Dua buah tumpeng untuk sesayut dilengkapi dengan raka-rakaan, seperti; bantal, tape, tebu, pisang, buahbuahan, jajan, kacang-kacangan (rerasmen) kemudian di atasnya diisi sampiyan sesayut dan ditambah penyeneng alit lengkap dengan isinya seperti tepung tawar, daun dapdap (daun kayu sakti), benang tetebus dan beras. Untuk lebih jelasnya perhatikan gambar 1 di bawah ini;

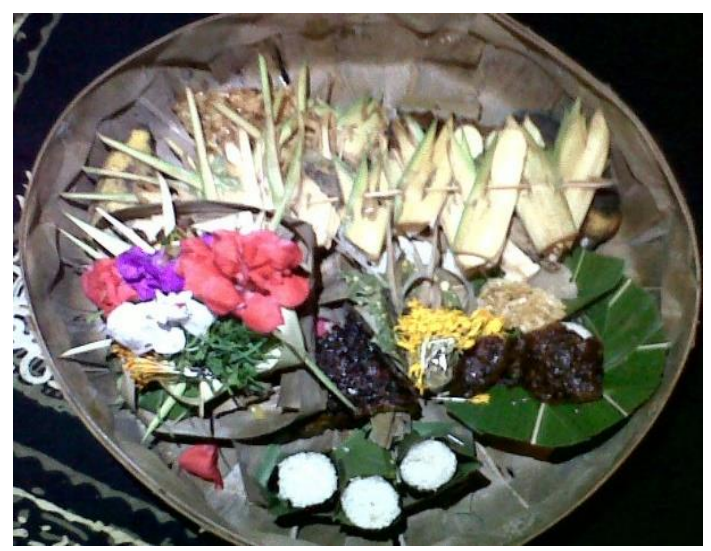

Gambar 1. Banten Sorohan

Sumber : Dokumentasi Peneliti, Tahun 2018.

\section{Banten Penguritan}

Terdiri dari: tipat nasi tiga biji, tipat blayag tiga biji diikat menjadi satu dilengkapi dengan raka-rakaan, seperti; bantal, tape, tebu, biyu, buah-buahan, jajan, kacang-kacangan (rerasmen), berisi sampiyan jerimpen mejit guak dan beralaskan sok besek serta di atasnya berisi canang sari. Perhatikan gambar 2 di bawah ini;

WIDYA DUTA | VOL. 16, NO. 2 |2021 


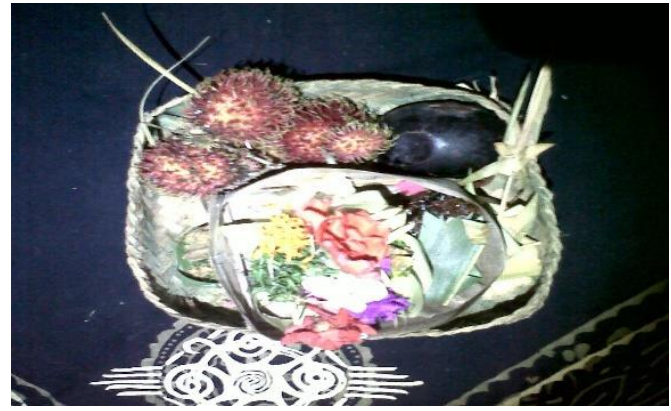

Gambar 2. Banten Penguritan

Sumber : Dokumentasi Peneliti, Tahun 2018.

\section{Sampiyan Banten Jerimpen di Wakul}

Terdiri dari: tipat nasi satu kelan, tipat blayag satu kelan, dilengkapi dengan raka-rakaan, seperti; bantal, tape, tebu, biyu, buah-buahan, jajan, kacangkacangan (rerasmen) berisi sampiyan jerimpen, lampat jalan yang beralaskan wakul di atasnya berisi canang sari. Lihat gambar 3 di bawah ini;

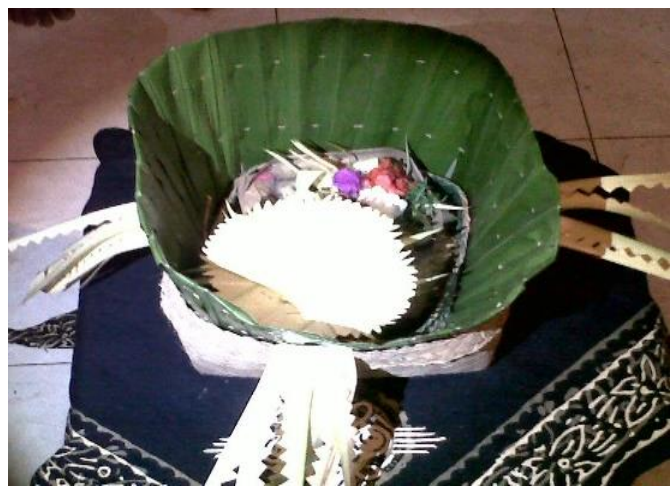

Gambar 3. Sampiyan Banten Jerimpen di Wakul

Sumber : Dokumentasi Peneliti, Tahun 2018.

\section{Banten Temuku}

Terdiri dari: tipat nasi satu biji, tipat blayag satu biji diikat menjadi satu kemudian dilengkapi dengan rakarakaan, seperti; bantal, tape, tebu, biyu, buah-buahan, jajan, kacang-kacangan (rerasmen) berisi sampiyan naga sari, di atasnya berisi canang sari dan beralaskan tamas. Untuk lebih jelasnya perhatikan gambar 4 di bawah ini;

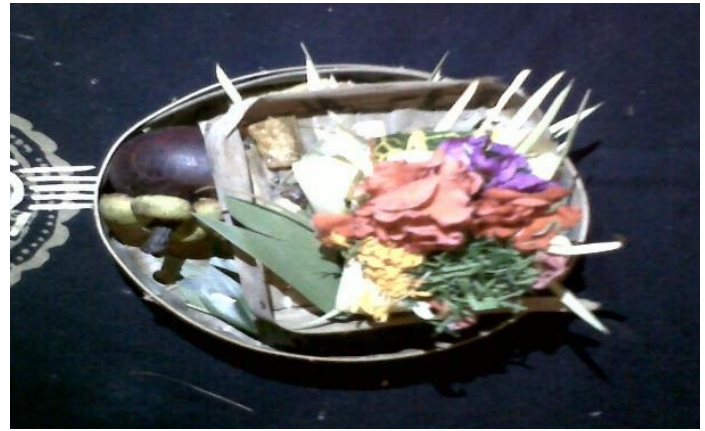

Gambar 4. Banten Temuku

Sumber : Dokumentasi Peneliti, Tahun 2018.

5. Banten Cau

Terdiri dari: Nasi, raka-rakaan seperti bantal, tape, tebu, biyu, buah-buahan, jajan, kacang-kacangan (rerasmen), rakan cau seperti; jajan selandangan, jajan bunga-bungaan, jajan bunga temu, jajan ipit, jajan gelang-gelangan, sampiyan cau, di atasnya diisi canang sari dan beralaskan sok bakul. Perhatikan gambar 5 berikut;

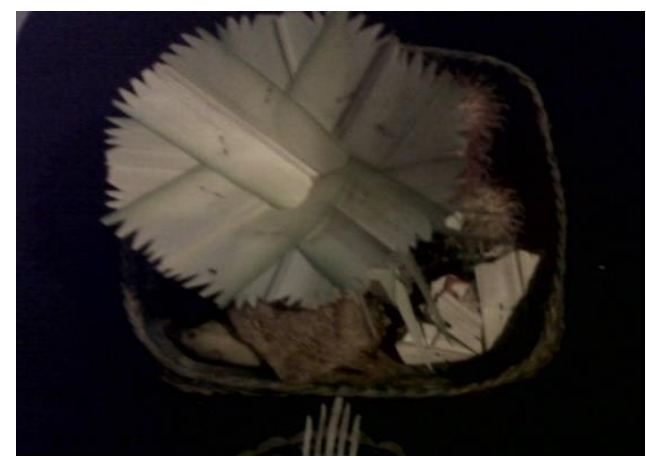

Gambar 5. Banten Cau

Sumber: Dokumentasi Peneliti, Tahun 2018.

\section{Sayut Pabersihan}

Terdiri dari: satu buah tumpeng, dilengkapi dengan raka-rakaan, seperti; bantal, tape, tebu, biyu, buah-buahan, jajan, kacang-kacangan (rerasmen), sampiyan naga sari ditambah tulung pebersihan dengan beralaskan sok besek di atasnya diisi canang sari. Lihat gambar 6 di bawah ini; 


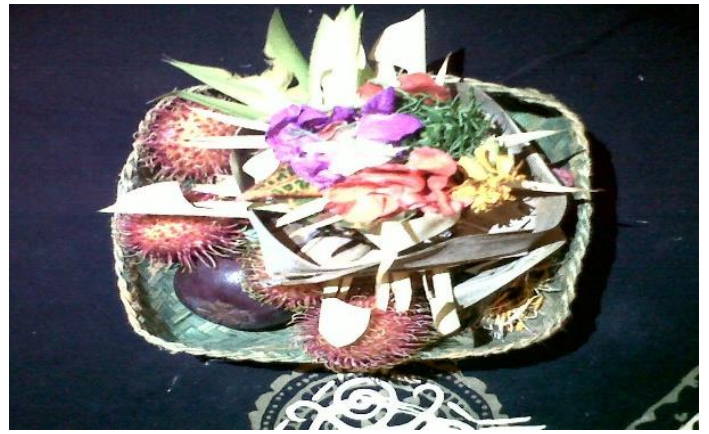

Gambar 6. Sayut Pebersihan

Sumber : Dokumentasi Peneliti, Tahun 2018.

\section{Canang Gede}

Terdiri dari: pelawa, porosan, wadah lengis (uras), di atas uras dihiyas dengan bunga harum lengkap dengan jajan, biyu, jajan selandangan, jajan gelanggelangan putih kuning. Beralaskan taledan dengan hiyasan tulang lindung. Perhatikan gambar 7 berikut ini;

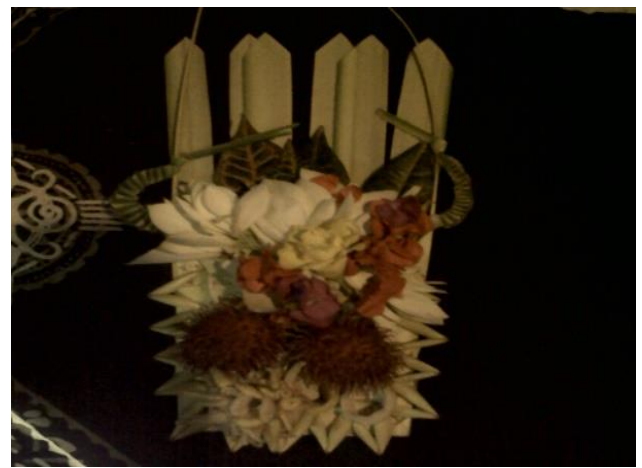

Gambar 7. Canang Gede

Sumber : Dokumentasi Peneliti, Tahun 2018

\section{Penjor Biyukukung}

Terdiri dari: pelepah enau, bakangbakang yang terbuat dari daun enau, sampiyan penjor, gantungan gubaggabig dan dihiyasi dengan pelawa. Perhatikan gambar 8 dan 9 berikut ini;

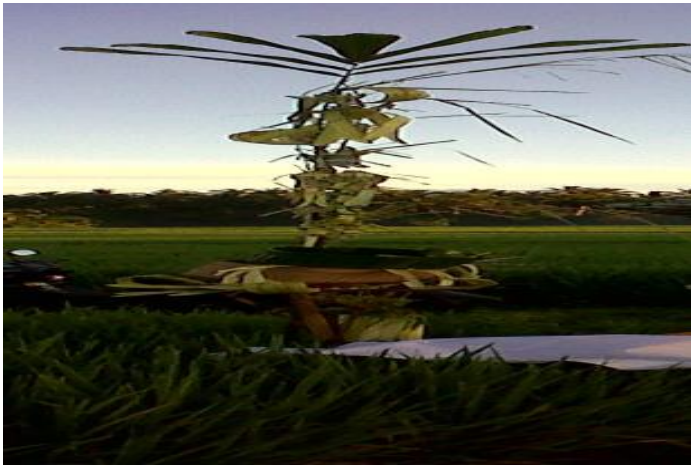

Gambar 8. Penjor Biyukukung

Sumber: Dokumentasi Peneliti, Tahun 2018.

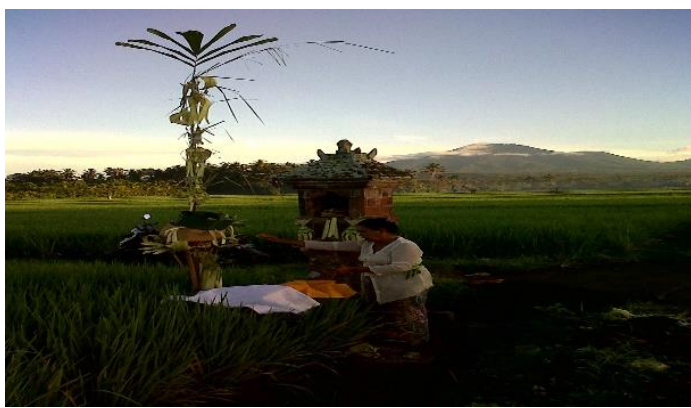

Gambar 9. Pemilik Sawah Sedang Menghaturkan Banten di Sanggah Cucuk/ Sanggah Penjor

Sumber: Dokumentasi Peneliti, Tahun 2018.

Di awali dengan memasang sanggah cucuk dihulu dekat temuku dan dilengkapi dengan penjor biyukukung lalu dipasang gantung-gantungan gubag-gabig diujungnya serta gantung -gantungan polos dipasang pada sanggah cucuk. Kemudian barulah dilanjutkan dengan menata banten, nunas tirta disanggah sedehan carik yang ada disawah dengan banten temuku. Selanjutnya pemilik sawah ngaturang banten yang ada disanggah cucuk dengan mantram/ sesontengan, sebagai berikut:

Sugra Ratu Bhetara Sri mangkin Ida Bhetara Sri pacang upakarain tiyang, mangkin katuran canang gede, banten jerimpen diwakul, pesucian, rauhin mangkin semeton sami mepupulan WIDYA DUTA | VOL. 16, NO. 2 |2021 
deriki ring ulu pacang upakarain tiyang, pang wusan mangkin ida Bhetara Sri ngerempini pang gelisgelis medal.

Terjemahannya:

Mohon maaf, Ratu Bhatara Sri sekarang Bhatara Sri akan hamba berikan upakara pabiyukukungan yaitu canang gede, banten jerimpen diwakul, pesucian. Agar berkumpul dihulu sawah akan hamba berikan upacara pabiyukukungan. Supaya Bhatara Sri berhenti ngidam, agar padinya cepet berisi (Ganter, Wawancara 23 Pebruari 2018).

1. Sanggah cucuk yang terbuat dari bambu dan di atasnya dibelah empat kemudian diisi/ dipasang kelatkat.

2. Keroso

Keroso ini dibuat dengan anyaman daun kelapa yang dibentuk melengkung menyerupai corong. Untuk lebih jelasnya perhatikan gambar 10 berikut ini;

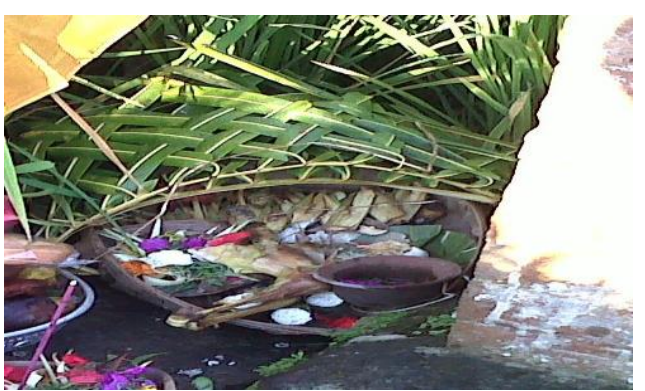

Gambar 10. Keroso

Sumber: Dokumentasi Peneliti, Tahun 2018.

3. Gebogan yang terdiri dari buah-buahan, jajan, beralaskan bokoran kemudian di atasnya di isi canang sari.

4. Rantasan putih kuning (kain yang berwarna putih dan kuning).

5. Kulit telor dan sarang lebah ini ditaruh di dalam keroso sebagai simbol/makna agar burung secara alami tinggal disarangnya.

\section{Fungsi Upacara Biyukukung}

Fungsi upacara biyukukung bagi petani sawah adalah supaya padi yang ditanam diberikan kerahayuan dan kesuburan agar pembuahannya berjalan dengan baik sehingga padi akan keluar butik yang lebat, serta dari sisi niskala bertujuan untuk mencegah segala macam hama dan serangga yang merusak. Upacara biyukukung juga berfungsi sebagai bentuk ungkapan rasa syukur dan terima kasih petani kepada Ida Sang hyang widhi Wasa atas berkah dan kesuburan yang telah dianugrahkan/ diberikan. Oleh karena itu, ungkapan rasa syukur para pemilik sawah disampaikan melalui jalan melaksanakan upacara biyukukung dengan mempersembahkan berbagai macam sarana upacara yang diwujudkan dalam bentuk banten.

\section{Fungsi Religius}

Nilai religius keagamaan adalah suatu nilai atau konsep mengenai penghargaan yang diberikan oleh warga masyarakat kepada beberapa masalah pokok dalam kehidupan keagamaan yang bersifat sakral dan suci, sehingga dapat dijadikan pedoman bagi tingkah laku beragama warga masyarakat bersangkutan (Wikarma, 1995). Berkaitan dengan hal tersebut masyarakat pemilik sawah di Subak Pupuan Luwah, Desa Pakraman Gadungan, Kecamatan Selemadeg Timur, Kabupaten Tabanan (hanya sebagai sampel) juga memberikan penghargaan yang tinggi sebagai pengalaman dan tradisi religiusitasnya dalam bercocok tanam padi. Salah satu wujudnya adalah pelaksanaan upacara biyukukung yang menggunakan 
berbagai macam sarana upacara. Dalam pelaksanaan upacara biyukukung, para petani berusaha menciptakan suasana yang khusuk dan kudus, sehingga prosesi upacara menjadi sakral dan dapat memberikan rasa tentram dan nyaman bagi para petani sawah maupun terhadap tumbuh-kembangnya pertumbuhan padi yang ditanamnya.

Menurut Koentjaraningrat (1981: 180) bahwa kebudayaan atau kultur adalah keseluruhan sisten gagasan, tindakan dan hasil karya manusia dalam rangka kehidupan bermasyarakat yang dijadikan proses pembelajaran. Proses pembelajaran inilah kemudian sangat penting untuk secara simultan dilaksanakan, agar dapat memberikan nuansa religius kepada segenap pelakunya. Apa yang diuraikan oleh Koentjaraningrat menjadi benar, bahwa upacara biyukukung adalah sebuah sistem gagasan manusia religius dan sebagai simbol penghargaan dan persembahan terhadap Dewi Sri dan Dewa Wisnu. Karena Beliau telah melindungi padi dari segala penyakit, hama, dan marabahaya sehingga tanaman padi dapat tumbuh dengan subur, berbunga, dan berbuah yang lebat. Para petani sawah menjadi sejahtera. Bagi masyarakat Hindu persembahan berupa upacara adalah siklus kehidupan, dimana manusia tidak hanya bisa mengambil/ menikmati kesejahteraannya saja, tetapi bagaimana manusia dapat menjaga rantai kehidupan ini secara berkesinambungan. Dengan persembahan/ yajna inilah diyakini oleh masyarakat Hindu di Bali sebagai cara ampuh untuk menjaga rantai kehidupan tetap berjalan secara seimbang dan harmonis. Dalam konteks ini, persembahan diyakini oleh masyarakat Hindu (baca petani sawah) sebagai dasar untuk memperoleh kesejahteraan hidup.
Sebagai masyarakat religius, persembahan (baca upacara byukukung) adalah suatu hal yang logis, karena dimana ada persembahan disana ada kesejahteraan. Dalam hal ini, upacara biyukukung dilaksanakan sebagai wujud cipta, rasa, dan karsa masyarakat petani kepada tumbuhan padi yang ditanamnya, sehingga padi diharapkan dapat tumbuh dengan subur, tanpa gangguan hama dan serangga yang dapat membahayakan tumbuh-kembangnya padi. Tradisi ini telah turun-temurun diwarisi dan dilakukan oleh masyarakat petani sawah sebagai wujud pelestarian budaya religius dalam bercocok tanam di sawah.

\section{Fungsi Sosial}

Di samping memiliki fungsi religius upacara biyukukung juga memiliki fungsi sosial, yaitu seberapa besar pengaruhnya terhadap pranata-pranata sosial (individu, keluarga, dan masyarakat). Ketika melaksanakan upacara, sudah barang tentu terdapat proses pelaksanaan dan lama waktu untuk mengerjakan upacara tersebut. Di dalam pengerjaan upacara inilah terdapat interaksi dan relasi individu, keluarga, dan masyarakat. Interaksi dan relasi sosial ini kemudian dijadikan sebagai wahana dan pendukung kehidupan bersosialitas. Kumpul bersama, mengerjakan upakara bersama, saling sapa diantara individu dengan individu, individu dengan kelompok, kelompok dengan kelompok, akan menimbulkan kehidupan bersama. Hidup bersama dalam kebersamaan inilah fungsi sosial itu tercipta dengan baik. Belajar bersama, bekerja bersama, saling tolongmenolong untuk mengerjakan upakara adalah sistem sosial yang diciptakan bersama melalui cara beragama Hindu yang 
benar dan dikemudian hari menjadi kehidupan sosial.

Sebagaimana diketahui bersama, bahwa manusia selain sebagai mahluk individu juga sebagai mahluk sosial yang dalam kehidupnya tidak bisa hidup sendiri tanpa bantuan orang lain. Manusia hanya akan mempunyai arti apabila ia hidup bersama dengan manusia lainya di dalam masyarakat. Seperti diuraikan dalam kitab Sarasamuscaya, sloka 4; "menjelma menjadi manusia adalah sangat utama dan mulia, karena manusia memiliki tiga unsur berupa tri premana, yaitu; bayu, sabda, dan idep". Pertama; bayu (kekuatan) adalah tenaga untuk melakukan aktivitas, Kedua; Sabda (suara) adalah kemampuan untuk berbicara sebagai alat untuk berkomunikasi, Ketiga; idep (pikiran) adalah kemampauan untuk menimbang-nimbang, memilah dan pada akhirnya dapat menentukan pilihan, mana yang baik dan mana yang buruk, serta mana yang benar dan mana yang salah. Ketiga keutamaan manusia itu tidak sama pada masing-masing individu. Menyadari akan kekurangan tersebut, maka manusia memerlukan bantuan serta pertolongan dari orang lain disekitarnya. Manusia dan juga alam ini memerlukan pengertian, kasih sayang, harga diri, dan tanggapan-tanggapan emosional yang sangat penting artinya bagi pergaulan dan kelangsungan hidupnya dalam bersosialitas.

Teori fungsional menyatakan bahwa untuk memuaskan kebutuhan peribadi yang tercermin dalam bentuk sosial pada sebuah aktivitas adalah suatu hal yang baik, sehingga berdampak pada suksesnya pelaksanaan upacara tersebut. Dalam kontek ini, pelaksanaan upacara biyukukung memiliki fungsi sebagai wahana meningkatkan kehidupan sosial, hal ini dapat dilihat dari proses pembuatan banten, dimana dari sejak mempersiapkan bahan upakara sampai pengerjaannya sudah terjadi interaksi sosial antara individu dengan individu, individu dengan keluarga, maupun keluarga dengan masyarakat. Untuk menjaga hubungan yang harmonis dalam keluarga maupun masyarakat, setiap individu memiliki etika dalam memenuhi kebutuhan hidup yang tidak bisa diabaikan begitu saja. Fungsi sosial tercermin dalam pelaksanaan upacara biyukukung dari sejak awal proses pemenuhan kelengkapan sarana upakara sampai pada pelaksanaan upacara tersebut selesai. Selalu saja melibatkan orang lain sehingga menimbulkan rasa kebersamaan dan kegotong-royongan yang tinggi antara sang yajamana dengan orang lain disekitarnya.

\section{Makna Upacara Biyukukung}

Pada hakikatnya manusia merupakan mahluk yang hidupnya senantiasa memproyeksikan makna ke dalam alam lingkungannya dimana mereka berada. Sehubungan dengan itu, manusia akan memberi makna kepada benda-benda, kemudian menumbuhkan nilai kepada benda atau bentuk-bentuk lainnya. Kecendrungan memberi nilai itu merupakan kegiatan kolektif yang dilakukan secara bersama oleh kelompok masyarakat sesuai dengan lingkungannya. Salah satunya upacara biyukukung yang merupakan wujud abstraksi pikiran manusia akan suatu hal yang mereka anggap bernilai dan bermakna. Melalui pelaksanaan upacara biyukukung mereka mengekspresikan nilai-nilai yang mereka anut dan dianggap baik serta berguna bagi hidup dan kehidupan semua mahluk, yang kelak nanti akan dijadikan dasar berperilaku, baik secara jasmani maupun rohani. 
Menurut Arimbawa (Wawancara, 16

Maret 2018) Upacara biyukukung merupakan aktivitas ritual yang mengandung makna bahwa manusia sebagai ciptaan Tuhan harus selalu bersyukur kepada Ida Sang Hyang Widhi Wasa atas segala karunianya, khususnya kepada para petani sawah yang telah berhasil dalam bidang pertanian sehingga hasilnya sesuai dengan yang diharapkan. Disamping itu sudah sepatutnya sebagai makluk ciptaan Tuhan khususnya manusia yang telah memiliki dan menikmati semua ciptaanNya wajib menyampaikan rasa terimakasih dan rasa bhaktinya kepada Tuhan/ Ida Sang Hyang Widhi Wasa. Pelaksanaan upacara biyukukung sebagai wujud persembahan bhakti kepada Tuhan mempunyai tujuan untuk memohon perlindungan terhadap alam semesta beserta isinya, dan upacara ini merupakan bagian dari usaha manusia sadar untuk mencapai tujuan yang lebih menekankan pada segi spiritual daripada hanya sekedar mengejar kebutuhan material belaka.

\section{Makna Teologi:}

Menurut Pudja (1999:3) dalam buku Teologi Hindu (Brahma Widya), menguraikan teologi berarti ilmu tentang Tuhan atau ketuhanan. Teologi dalam pandangan Hindu disebut dengan Brahma Widya, karena Brahma Widya pada hakikatnya adalah ilmu yang mempelajari tentang Tuhan dengan segala aspeknya. Di dalam sastra sanskerta dan berbagai kitab suci lainnya, teologi diartikan sebagai ilmu yang mempelajari tentang Tuhan. Teologi juga sering disebut Brahma Widya atau Brahma Tattwa Jnana. Kata Brahma dalam hubungan pengertian tersebut diartikan Tuhan, yaitu gelar yang diberikan kepada Tuhan sebagai unsur yang memberi kehidupan pada semua ciptaanNya dan juga unsur sabda dan aksara (Yang Maha Kuasa). Sedangkan jnana artinya ilmu, pengetahuan, dan tattwa artinya hakikat tentang "tat" itu sendiri, yaitu Tuhan dalam bentuk Nirguna Brahman. Dengan demikian "Brahma Jnana Tattwa" berarti hakikat pengetahuan tentang Tuhan dengan segala aspeknya. Artinya Brahma Widya mengupas dan membicarakan secara mendalam tentang hakikat Tuhan dengan segala manifestasinya.

Setiap kegiatan ritual keagamaan yang dilaksanakan tentu memiliki makna Teologi, karena Teologi sendiri tidak bisa dilepaskan dari ajaran-ajaran Agama. Teologi tidak dapat dipisahkan dari suatu keyakinan itu sendiri. Agama Hindu memiliki dua sistem Teologi yaitu Nirguna Brahman dan Saguna Brahman. Dalam Nirguna Brahman dimana Tuhan tidak dapat dimanifestasikan sedangkan dalam Saguna Brahman Tuhan dapat diwujudkan atau didefinisikan dalam berbagai bentuk dan perwujudan. Implementasi dan sistem Teologi Saguna Brahman dalam aktivitas keseharian masyarakat Hindu diwujudkan dalam berbagai bentuk dan simbol-simbol yang diyakini sebagai perwujudan kekuatan yang dimiliki oleh Ida Sang Hyang Widhi Wasa, seperti; arca, pratima, yantra, mantra, termasuk pula diwujudkan melalui media persembahan berupa banten dan upakara.

Teologi Hindu adalah ajaran ketuhanan yang erat kaitannya dengan simbol-simbol dalam Agama Hindu, karena simbol-simbol tersebut merupakan ekspresi untuk mendekatkan diri manusia kepadaNya. Simbol-simbol tersebut berupa arca atau pratima dewa-dewa, wahana dewata atau kendaraan dewa-dewa, bangunan suci sebagai stana untuk memuja 
para dewata atau roh suci leluhur. Disamping juga berupa mantra, mudra, yantra, hurup-hurup suci, juga persembahan suci berupa sesajen yang beraneka ragam bentuknya (Titib, $2003: 1$ ).

Berpikir tentang Tuhan berarti seseorang harus mengenal Tuhan dalam kenyataannya, baik sebagai hakikat yang dikenal sebagai Nirguna Brahman maupun sebagai aspek Saguna Brahman (Pudja, 1999:6). Brahma Widya atau Teologi memiliki objek tentang pengetahuan Nirguna Brahman dan Saguna Brahman. Nirguna Brahman merupakan pengetahuan Tuhan yang tidak dapat dibayangkan, hanya dapat diterapkan oleh orang-orang yang tidak terikat degan kesadaran badan fisik, sedangkan Saguna Brahman merupakan pengetahuan Tuhan yang dapat dipikirkan dan dapat digambarkan, serta diterapkan oleh siapa saja karena Tuhan dapat diwujudkan berupa simbol-simbol. Dengan penggambaran tersebut manusia mudah mewujudkan baktinya kepada Tuhan yang serba maha tersebut. Secara abstrak oleh manusia, Tuhan dilukiskan sebagai maha mendengar, maha melihat, maha mengetahui, maha kuasa, maha pencipta, maha pengasih dan penyayang, dan lain sebagainya, yang kesemua sifat-sifat Tuhan itu adalah sifat yang didambakan oleh manusia sebagai pemujaNya (Pudja, 1999:21). Dalam Bhagawadgita XII.5 dinyatakan :

Kleśo dhikataras tesām avyaktāsakta cetasām,avyaktā hi gatir dhukhaṃ dehavadbhir avāpyate.

Terjemahannya :

Bagi mereka yang pikirannya dipusatkan kepada yang tak terwujud, kesulitannya lebih besar, karena sesungguhnya jalan dari yang tak termanifestasikan sukar dicapai oleh orang yang mempunyai badan jasmani (Pudja, 2004: 285).

Petikan sloka di atas dapat memberikan suatu pemahaman bahwa mencari Tuhan yang teransendental (tak berwujud) jauh lebih sulit dari pada Tuhan yang 'berwujud' (baca; Ista Dewata). Jalan bhakti merupakan jalan yang mudah dilakukan untuk mencapai Tuhan yang berperibadi, dengan mengalihkan seluruh pikiran, tenaga, maupun perasaan kepadaNya. Memuja Tuhan yang berwujud baik itu berupa pratima, hurup-hurup suci, patung-patung, maupun dengan sarana simbol-simbol tertentu lainnya merupakan suatu jalan pemujaan yang mudah dilakukan untuk mendekatkan diri kepada Tuhan.

Dalam perspektif Saguna Brahman inilah muncul penggunaan simbol-simbol (nyasa) yang digunakan untuk membayangkan kehadiran Tuhan seperti penggunaan pratima, gambar-gambar, persembahan sesajen (banten) dan simbol lainnya. Pada tahap Apara Bhakti ini, secara umum masyarakat lebih banyak terlibat dalam aktivitas (ritual) keagamaan yang menggunakan simbol untuk mendekatkan diri kepada Tuhan. Berkaitan dengan hal tersebut di atas maka upacara biyukukung mengandung makna Teologi yaitu sebagai persembahan kepada Tuhan Yang Maha Esa/ Ida Sang Hyang Widhi Wasa atas segala anugrahNya dalam manifestasi Beliau sebagai Dewi Sri dan Dewa Wisnu yang telah memelihara dan memberi kekuatan dan kehidupan pada tumbuhan padi. Atas semua asung kertha waranugraha Tuhan dalam manifestasinya sebagai Dewi Sri dan Dewa Wisnu tersebut, bibit kesejahteraan yang berupa padi dapat dinikmati oleh manusia 
khususnya masyarakat petani subak (sawah).

Dengan demikian makna teologi rangkaiannya adalah sebagai sebuah rasa bhakti dan pembebasan petani terhadap tanaman padi yang di tanamnya kepada sang pencipta itu sendiri. Dengan melaksanakan upacara yang bersadhanakan bhakti berupa banten masyarakat petani merasa telah menunaikan swadharma secara agama Hindu, sehingga semua apa yang diharapkan dapat tercapai dengan baik dan panenan menjadi melimpah-ruah. Petani padi di sawah menjadi makmur.

Jadi benar apa yang dikatakan Surayin bahwa Banten juga disebut upakara, upakara terdiri dari dua suku kata yaitu upa dan kara. Upa berarti mendekat, kara artinya tangan, aktivitas, bhakti. Jadi upakara berarti dengan aktivitas bhakti para petani mendekatkan diri kepada Tuhan Yang Maha Esa (Surayin, 2005: 4). Dalam upacara biyukukung menggunakan sarana banten dalam persembahan. Sarana banten tersebut memiliki makna tersendiri. Maknamakna yang ada bertujuan untuk menambah serta meningkatkan keyakinan umat Hindu terhadap pelaksanaan upacara yang sedang diselenggarakan. Makna banten yang terdapat dalam upacara biyukukung antara lain;

1. Keroso merupakan simbol sarang burung; dengan sarana simbolik ini secara alami burung diharapkan tetap tinggal disarangnya secara alami dan tidak merusak tanaman padi yang sedang berbuah.

2. Sanggah cucuk adalah sebuah tempat suci yang terbuat dari bambu yang dianyam berbentuk segi empat.
Sanggah cukcuk merupakan simbol sthananya Dewi Sri.

3. Penjor merupakan simbol gunung yang memberikan keselamatan dan kesejahteraan, penjor juga merupakan lambang pertiwi dengan segala hasilnya yang memberikan kehidupan dan keselamatan.

4. Canang gede dan gebogan berfungsi sebagai ungkapan rasa syukur kehadapan Dewi Sri atas berkat dan rahmat-Nya sehingga tanaman padi tersebut dapat tumbuh dengan subur, berbunga dan berbuah yang lebat.

5. Banten jerimpen diwakul dan banten cau adalah merupakan simbol permohonan kehadapan Tuhan beserta manifestasiNya (Asta Aiswarya) agar Beliau memberikan waranugraha secara lahiriah dan bathiniah (Suwendri, Wawancara 3 Mei 2018).

Demikian makna yang terkandung dalam banten yang dipergunakan pada saat upacara biyukukung di Subak Pupuan Luwah, Desa Pakraman Gadungan, Kecamatan Selemadeg Timur, Kabupaten Tabanan.

\section{PENUTUP}

Simpulan

Dari hasil analisis terhadap prosesi upacara biyukukung yang dilaksanakan oleh petani subak (sawah) adapun runtutan ritual yang dilakukan diawali dengan persiapan sarana dan prasarana upakara/ banten serta kelengkapan lainnya yang dipergunakan dalam upacara tersebut. Upacara biyukukung merupakan sebuah upacara untuk tumbuhan padi yang sedang berbuah (padi yang sedang mengandung), yang berfungsi sebagai sarana untuk memohon keselamatan agar padi tumbuh dengan 
subur, berbunga, dan berbuah yang lebat, tanpa gangguan serangga, burung, dan hama penyakit lainnya yang dapat membahayakan tumbuh-kembangnya padi.

Dalam kepercayaan umat Hindu Bali khususnya makna upacara biyukukung adalah sebagai ungkapan puji syukur petani subak kepada Tuhan Yang Maha Esa dalam wujud manifestasinya sebagai Dewi Sri dan Dewa Wisnu yang telah memberikan keselamatan dan tumbuh-kembangnya padi dengan subur, terhindar dari segala hama penyakit, dan marabahaya lainnya. Upacara biyukukung juga bermakna sebagai wujud persembahan dan bhakti kepada Tuhan yang telah menganugrahkan kesuburan pada tumbuhan padi. Sebagai masyarakat yang religius upacara biyukukung adalah wujud pengejawantahan dari keyakinan dan kepercayaan masyarakat petani terhadap kebesaran Tuhan dan kemahakuasaanNya yang telah memelihara padi secara niskala dari segala marabahaya, sehingga rantai kehidupan dapat berjalan secara seimbang, harmonis, dan berkesinambungan. Untuk makna itulah masyarakat Bali melaksanakan tradisi upacara biyukukung yang telah diwarisi secara turun-temurun dari nenek moyang mereka sejak dahulu kala. Sehingga secara Teo-Agrikultur upacara Biukukung secara tidak langsung mendorong manusia untuk bertani secara ramah lingkungan agar terjaga kelestarian alam, menghargai alam dan bersyukur dengan apa yang diberikan dan dihasilkan alam. Teo-Agrikultur secara kontekstual mendorong manusia untuk bertani dengan tidak hanya memikirkan keuntungan pribadi, melainkan akan mengupayakan keuntungan dan kesejahteraan bagi alam. Dalam teologi ini manusia sadar bahwa dirinya bergantung kepada alam dan alam tergantung kepada manusia. Keduanya berada dalam rantai kehidupan yang saling mengisi satu dengan lain.

\section{DAFTAR PUSTAKA}

Arwati, Ni Made Sri, 2005. Perwujudan Upakara untuk Upacara Agama Hindu. Denpasar: Upada Sastra.

Arwati, Ni Made Sri, 2007. Upacara Bercocok Tanam Di Sawah. Denpasar: Upada Sastra.

Koentjaraningrat, 1991. Metodelogi Penelitian Masyarakat. Jakarta: Gramedia Pustaka Pelajar.

Koentjaraningrat, 1997. Pengantar Antropologi Pokok-Pokok Etnografi II. Jakarta: Reneka Cipta.

Lewis, H.D. dan Robert Lawson Slater, 1966. World Relegions. London: C.A. Watts.

Mas-Putra, I Gusti Agung, 2000. Upakara Yadnya. Denpasar: Dinas Pendidikan Dasar Provinsi Bali.

Pudja, Gde, 2004. Bhagawadgita. Surabaya: Paramita.

Pudja, Gde, 1999. Teologi Hindu (Brahma Widya). Paramita: Surabaya.

Radhakrishnan and charles A. Moore (eds), 1957. A Source Book in Indian Philosophy. Princeton: Princeton U. Press.

Titib, I Made, 2003. Teologi dan SimbolSimbol dalam Agama Hindu. Surabaya: Paramita.

Titus, Harold H., 1984. Persoalan-Persoalan Filsafat. Alih bahasa H.M. Rasjidi. Bandung: Bulan Bintang.

Wijayananda, Ida Pandita Empu Jaya, 2006. Makna Filosofis Upacara dan Upakara. Surabaya: Paramita.

Wikarman, I Nyoman Singgin, 1995. Aci-Aci Bercocok Tanam Padi. Bangli: Yayasan Widya Shanty. 
Lontar: Bhagawan Sukra, Nomor: 3b.

Denpasar: Pusat Dokumentasi

(Pusdok).

Narasumber: (1) Ni Wayan Ganter, (2) I Made Arimbawa, dan (3) Ni Wayan Suwendri. 